\title{
Globe
}

Revue internationale d'études québécoises

\section{Parutions récentes en études québécosies}

\section{Sébastien Dulude}

Volume 10, numéro 1, 2007

Étranger et territorialité

URI : https://id.erudit.org/iderudit/1000086ar

DOI : https://doi.org/10.7202/1000086ar

Aller au sommaire du numéro

Éditeur(s)

Globe, Revue internationale d'études québécoises

ISSN

1481-5869 (imprimé)

1923-8231 (numérique)

Découvrir la revue

Citer ce document

Dulude, S. (2007). Parutions récentes en études québécosies. Globe, 10(1),

197-201. https://doi.org/10.7202/1000086ar d'utilisation que vous pouvez consulter en ligne.

https://apropos.erudit.org/fr/usagers/politique-dutilisation/ 


\title{
PARUTIONS RÉCENTES EN ÉTUDES QUÉBÉCOISES
}

\author{
1" novembre 2006 au $1^{\text {er }}$ mai 2007 \\ Sébastien Dulude [éd.]
}

\begin{abstract}
$++4+4+4+4++4+4+4++4+4++$
Nos lecteurs sont invités à nous faire part des parutions récentes en études québécoises publiées à l'étranger.
\end{abstract}

Sylvie Alix et France Gascon [éd.], Graphzines et autres publications d'artistes, Montréal, Bibliothèque et Archives nationales du Québec, 2007, ISBN 978-2-55122999-4 [catalogue d'exposition].

Pascale Beaudet [éd.], L'art public à Montréal. À propos de quelques œuvres extérieures, Montréal, Centre d'exposition Circa, 2007, ISBN 978-2-9809866-0-4 [catalogue d'exposition].

Louise Beaudoin et François Dorlot, René Levesque, Montréal, Éditions La Presse, coll. «Passions», 2007, ISBN 978-2-923194-41-7.

Louise Beaudoin et Liza Frulla [propos recueillis par Danièle Bombardier], Amitié interdite, Montréal, Éditions La Presse, 2007, ISBN 978-2-923194-40-0.

Michel Biron, François Dumont et Élisabeth Nardout-Lafarge [avec la collaboration de Martine-Emmanuelle Lapointe], Histoire de la littérature québécoise, Montréal, Boréal, 2007, ISBN 978-2-7646-0522-6.

Gérard Bouchard et Alain Roy, La culture québécoise est-elle en crise?, Montréal, Boréal, 2007, ISBN 978-2-7646-0519-6.

Denise Brassard, Le souffle du passage. Poésie et essai chez Fernand Ouellette, Montréal, VLB, coll. "Les champs de la culture», 2007, ISBN 978-2-89005-967-2. 
Jason Camlot et Todd Swift [ed.], Language Acts. Anglo-Québec Poetry, 1976 to the $21^{\text {tt }}$ Century, Montréal, Véhicule Press, 2007, ISBN 978-1-55065-225-3.

Jean-Claude Corbeil, L'embarras des langues, Montréal, Québec Amérique, 2007, ISBN 978-2-7644-0562-8 [politique linguistique québécoise].

Martine D'Amours, L'économie sociale au Québec. Cadre théorique, histoire, réalités et défis, Montréal, Éditions Saint-Martin, 2006, ISBN 978-2-89035-408-1.

Fabrice de Pierrebourg, Montréalistan. Enquête sur la mouvance islamiste, Montréal, Stanké, 2007, ISBN 978-2-7604-1040-4 [terrorisme au Québec].

Dominique Deslandres, John Dickinson et Ollivier Hubert [éd.], Les Sulpiciens de Montréal. Une histoire de pouvoir et de discrétion, 1657-2007, Saint-Laurent, Fides, 2007, ISBN 978-2-7621-2727-0.

Louise H. Forsyth [éd.], Anthology of Québec Women's Plays in English Translation. Vol. 1, 1966-1986, Toronto, Playwrights Canada Press, 2006, ISBN 0-88754-8687.

Yolande Geadah, Accommodements raisonnables. Droit à la différence et non différence des droits, Montréal, VLB, coll. "Partis pris actuels", 2007, ISBN 978-2-89005-9993 [sur le multiculturalisme québécois].

Anne-Renée Gravel, Guy Bellemare et Louise Briand, Les centres de la petite enfance. Un mode de gestion féministe en transformation, Sainte-Foy, Presses de l'Université du Québec, coll. "Pratiques et politiques sociales et économiques", 2007, ISBN 978-27605-1484-3.

Pierre Graveline, Une histoire de l'éducation au Québec, édition revue et mise à jour, Saint-Laurent, Bibliothèque québécoise, 2007, ISBN 978-2-89406-286-9.

Annette Hayward, La querelle du régionalisme au Québec, 1904-1931. Vers l'autonomisation de la littérature québécoise, Ottawa, Le Nordir, coll. "RogerBernard", 2006, ISBN 978-2-89531-049-5.

Chantal Hébert, French kiss. Le rendez-vous de Stephen Harper avec le Québec [traduction de French Kiss par Suzanne Anfossi], Montréal, Éditions de l'Homme, 2007, ISBN 978-2-7619-2369-9.

François Hébert, Dans le noir du poème. Les aléas de la transcendance chez quelques poètes québécois, Saint-Laurent, Fides, coll. "Nouvelles études québécoises", 2007, ISBN 978-2-7621-2632-7. 
Pascal Jacob et Michel Vézina, Désir(s) de vertige. 25 ans d'audace, Montréal, Les 400 coups, 2007, ISBN 978-2-89540-342-5 [sur l'École nationale de cirque de Montréal].

André Lachance, Séduction, amour et mariages en Nouvelle-France, Montréal, Libre expression, 2007, ISBN 978-2-7648-0337-0.

Andrée Lajoie [éd.], Gouvernance autochtone. Aspects juridiques, économiques et sociaux, Montréal, Editions Thémis, 2007, ISBN 978-2-89400-225-4.

André Larocque, Le parti de René Lévesque. Une vue de l'intérieur, Montréal, Fides, 2007, ISBN 978-2-7621-2788-1.

Georges Leroux, Ethique et culture religieuse. Un programme de formation pour la société québécoise, Saint-Laurent, Fides, coll. "Les grandes conférences", 2007, ISBN 978-2-7621-2789-8.

Éric Méchoulan et Marie-Louise Ollier [éd.], Paul Zumthor. Traversées, Montréal, Presses de l'Université de Montréal, 2007, ISBN 978-2-7606-2046-9.

Richard Morin, La régionalisation au Québec. Les mécanismes de développement et de gestion des territoires régionaux et locaux. 1960-2006, Montréal, Editions SaintMartin, 2006, ISBN 978-2-89035-406-7.

Réjean Olivier, Théâtre, musique, beaux-arts. Traditions culturelles et artistiques au Collège de L'Assomption, 1833-1974, $2^{c}$ éd., Joliette, Édition privée, coll. "CEuvres bibliophiliques de Lanaudière", 2007, ISBN 978-2-920904-62-0.

Pierre Pagé, Radio-culture et société québécoise, 1900-1982. Le rôle des radios privées, linfluence de Radio-Canada, Saint-Laurent, Fides, 2007, ISBN 978-2-7621-2770-6.

Martin Petitclerc, Nous protégeons l'infortune. Les origines populaires de l'économie sociale au Québec, Montréal, VLB, coll. "Études québécoises", 2007, ISBN 978-289005-966-5.

Ginette Plessis-Bélair, Lizanne Lafontaine et Réal Bergeron [éd.], La didactique du français oral au Québec. Recherches actuelles et applications dans les classes, Sainte-Foy, Presses de l'Université du Québec, coll. "Éducation-recherche», 2007, ISBN 978-27605-1418-8.

Sylvain Rivière, La mer nourricière. 1890-1972, Québec, Publications du Québec, coll. "Aux limites de la mémoire», 2007, ISBN 978-2-551-19631-9 [sur l'histoire des pêches québécoises]. 
Jocelyn Saint-Pierre, Histoire de la Tribune de la presse à Québec, 1871-1959, Montréal, VLB, coll. «Etudes québécoises», 2007, ISBN 978-2-89005-970-2.

Anne-Marie Sicotte, Femmes de lumière. Les religieuses québécoises avant la Révolution tranquille, Saint-Laurent, Fides, 2007, ISBN 978-2-7621-2695-2.

Michel van Schendel, Ecrits politiques, Montréal, VLB, coll. "Les champs de la culture", 2007, ISBN 978-2-89005-969-6.

Jean-Philippe Warren, De La croyance. Le militantisme marxiste-léniniste au Québec, Montréal, VLB, coll. «Études québécoises", 2007, ISBN 978-2-89005-990-0.

\section{TRADUCTIONS}

Marie-Claire Blais, Deaf to the City, [traduction de Le sourd dans la ville par Carol Dunlop], Toronto, Exile Editions, coll. "Exile classics», 2006, ISBN 1-55096-013$\mathrm{X}$.

Marie-Claire Blais, Nights in the Underground [traduction de Les nuits de l'underground par Ray Ellenwood], Toronto, Exile Editions, coll. "Exile classics", 2006, ISBN 1-55096-015-6.

Pascal Blanchet, White Rapids [traduction de Rapide blanc], Montreal, Drawn \& Quarterly Books [à paraître].

Nicole Brossard, Notebook of Roses and Civilization [traduction de Cahier de roses \& de civilisation par Robert Majzels et Erin Mouré], Toronto, Coach House Books, 2007, ISBN 978-1-55245-181-6.

Leonard Cohen, Livre du constant désir [traduction de Book of Longing par Michel Garneau], Montréal, L'Hexagone, coll. "L'appel des mots", 2007, ISBN 978-289006-791-2.

Martine Desjardins, $A$ Covenant of Salt [traduction de L'évocation par David Homel et Fred A. Reed], Vancouver, Talonbooks, 2007, ISBN 978-0-88922-566-4.

Hélène Dorion, Days of Sand [traduction de Jours de sable par Jonathan Kaplansky], Toronto, Cormorant Books, 2007, ISBN 978-1-897151-075.

Carole Fréchette, Two Plays [traduction de Le collier d'Hélène et Jean et Béatrice par John Murrell, Toronto, Playwrights Canada Press, 2007, ISBN 978-0-88754-501-6.

Robert Marteau, Pig-Skinning [traduction de Le jour qu'on a tué le cochon par David Homel], Toronto, Exile Editions, coll. "Picas series", 2006, ISBN 1-55096-038-5. 
Daniel Poliquin, $A$ Secret Between $U s$ [traduction de La kermesse par Donald Winkler], Vancouver, Douglas \& McIntyre, 2007, ISBN 978-1-55365-272-4.

Jacques Poulin, My Sister's Blue Eyes [traduction de Les yeux bleus de Mistassini par Sheila Fischman], Toronto, Cormorant Books, 2007, ISBN 978-1-897151-05-1.

Jacques Poulin, Spring Tides [traduction de Les grandes marées par Sheila Fischman], Toronto, Cormorant Books, 2007, ISBN 978-1-897151-14-3.

Michel Tremblay, Assorted Candies for the Theatre [traduction de Bonbons assortis au théâtre par Linda Gaboriau], Vancouver, Talonbooks, 2007, ISBN 978-0-88922$572-5$.

André Vanasse, Gabrielle Roy. A Passion for Writing [traduction de Gabrielle Roy. Ecrire, une vocation par Darcy Dunton], Montréal, XYZ Pub., coll. "The Quest library", 2007, ISBN 978-1-894852-25-8. 